\title{
A theory of political and economic cycles
}

\author{
Laurence Ales $^{\text {a }}$, Pricila Maziero ${ }^{\mathrm{b}}$, Pierre Yared $^{\mathrm{c}, \mathrm{d}, *}$ \\ a Tepper School of Business, Carnegie Mellon University, United States \\ $\mathrm{b}$ The Wharton School, University of Pennsylvania, United States \\ ${ }^{\mathrm{c}}$ Graduate School of Business, Columbia University, United States \\ ${ }^{\mathrm{d}}$ The National Bureau of Economic Research (NBER), United States
}

Received 20 May 2013; final version received 3 July 2014; accepted 4 July 2014

Available online 9 July 2014

\begin{abstract}
We develop a theoretical framework in which political and economic cycles are jointly determined. These cycles are driven by three political economy frictions: policymakers are non-benevolent, they cannot commit to policies, and they have private information about the tightness of the government budget and rents. Our first main result is that, in the most favorable equilibrium to the households, distortions to production emerge and never disappear even in the long run. This result is driven by the interaction of limited commitment and private information on the side of the policymaker, since in the absence of either friction, there are no long run distortions to production. Our second result is that, if the variance of private information is sufficiently large, there is equilibrium turnover in the long run so that political cycles never disappear. Finally, our model produces a long run distribution of taxes, distortions, and turnover, where these all respond persistently to temporary economic shocks.
\end{abstract}

(c) 2014 Elsevier Inc. All rights reserved.

JEL classification: H21; P16; E62; D82

Keywords: Optimal taxation; Political economy; Fiscal policy; Asymmetric and private information

\footnotetext{
* Corresponding author.

E-mail addresses: ales@cmu.edu (L. Ales),maziero@wharton.upenn.edu (P. Maziero), pyared@ columbia.edu (P. Yared).
} 


\section{Introduction}

Economic and political cycles are deeply interconnected. On the one hand, economic shocks impact the tenure of leaders, as incumbents are often replaced following negative economic shocks. On the other hand, political risk and the threat of turnover can often induce policymakers facing potential replacement to become shortsighted and to choose inefficient policies.

For example, the collapse of commodity prices in the late 1970s and early 1980s caused a sharp decline in government revenues in many sub-Saharan African countries. Unable to fund public services, leaders faced the threat of removal. In some cases, they responded to this threat by taking measures which increased social programs while simultaneously expropriating private enterprises, further exacerbating the economic crisis. ${ }^{1,2}$

In this paper, we develop a framework in which political and economic cycles are jointly determined. In our environment, these cycles are driven by three key political economy frictions. First, policymakers are not benevolent, and are instead driven by political rents and by the desire to preserve power. Second, policymakers lack commitment, and once in office, they are not bound to the promises which they made to citizens. Finally, policymakers have private information about the tightness of the government budget and their rent-seeking activities. We embed these frictions in an environment which combines two frameworks. The first framework is a standard political accountability model with asymmetric information in which citizens can punish incumbents with replacement. The second framework is a dynamic production economy with rent-seeking.

More formally, our economy is populated by households which choose investment and a non-benevolent policymaker who chooses taxes and rents. The policymaker cannot commit to policies after households have made their investment decision, and households discipline the policymaker by threatening to replace him. The government controls a stochastic endowment, where this captures a shock to the value of government royalties or to the cost of public spending. The policymaker privately observes the size of this shock and privately chooses the level of rents. This implies that if citizens observe high taxes, they may not be able to determine whether this is due to an exogenous aggregate shock which tightened the budget or whether this is due to unobserved rent-seeking by the policymaker.

We consider the equilibrium which maximizes the ex-ante welfare of citizens, and we characterize the dynamics of distortions to production (economic cycles) and the dynamics of political turnover (political cycles). The equilibrium takes into account the joint interaction of the constraints of limited commitment and private information on the side of the policymaker. We show how in the absence of either friction, there are no distortions to production-and thus, no economic cycles-since the level of investment is efficiently chosen in the long run. In the absence of asymmetric information, for instance, our model features backloading. Specifically, a policymaker is never replaced, though if he deviates by expropriating households, he is replaced off the equilibrium path. While distortions emerge along the equilibrium path in order to limit the resources which can be expropriated by the policymaker, these distortions eventually disappear

\footnotetext{
1 See Bates [18] for further discussion of these episodes. As an example, following the collapse of copper prices, President Kaunda of Zambia nationalized several milling companies, imposed price controls, and limited government debt service as part of the Interim New Economic Recovery Programme. Between 1988 and 1991, investment in Zambia declined by $17 \%$. See Baylies and Szeftel [20] and Simutanyi [54] for additional discussion.

2 As an another example, many Latin American countries dependent on commodity exports experienced economic and political crises following the collapse of commodity prices in the late 1970s and early 1980s. For a discussion of the experience of Mexico, see Bergoeing et al. [21], for example.
} 
as rents rise and reduce his incentives to expropriate. Note that the absence of long run distortions under full information is not unique to our model, but common across a large class of full information principal-agent environments in which the agent suffers from limited commitment, as in Acemoglu et al. [1-3], for example. ${ }^{3}$ Analogously, under asymmetric information and in the presence of full commitment, there are never distortions to production. Because the policymaker has limited discretion over the choice of taxes under full commitment, the payoffs from his decisions are independent of the level investment. As such, distortions to production cannot facilitate incentive provision and they never appear. Therefore, under either full information or full commitment, there are no long run distortions to production.

The first main result of our paper is that distortions to production emerge and never disappear, even in the long run. This feature of our model is a consequence of the joint interaction of the limited commitment and the asymmetric information frictions. This result is due to the fact that a policymaker is always provided with dynamic incentives to not privately rent-seek. More specifically, if a shock tightens (slackens) the budget constraint so that observed taxes are high (low), then the policymaker is punished (rewarded) in the future with lower (higher) payment. Eventually a long sequence of negative shocks push payments to the policymaker sufficiently down that the policymaker becomes tempted to fully expropriate the investment of households. Anticipating this threat, households invest less, so that distortions to production eventually emerge as a means of preventing full expropriation. This result arises as a consequence of optimality and not feasibility since allocations in which there are no distortions to production are a possibility in an equilibrium in our environment; however, they are suboptimal since they do not entail enough risk-sharing between households and the policymaker. Importantly, this result holds for any variance in the private information of the policymaker. Therefore, the introduction of privately observed uncertainty to the full information benchmark leads to the presence of long run distortions, altering the predictions of the full information benchmark.

The second main result of our paper is that there is turnover in the long run if the variance of the private information of the policymaker is sufficiently large. This is because, if the variance of private information is large, then the policymaker has high private rent-seeking opportunities, and replacement is a useful means of preventing private rent-seeking. More specifically, society has two tools for providing incentives to policymakers to not privately rent-seek. On the one hand, society can directly pay higher future rents to reward policymakers who choose low taxes today. Though this costs societal resources, it reduces the policymaker's incentives to fully expropriate households since he values preserving power, and it allows households to choose the efficient level of investment today. On the other hand, society can instead punish policymakers who choose high taxes by removing them from office in the future. This does not cost any societal resources, but it raises a policymaker's incentives to fully expropriate households today since the horizon of the policymaker is reduced. In response, households are forced to invest less today, causing economic distortions. If the variance of private information is large, then a policymaker has high private rent-seeking opportunities, and providing incentives to the policymaker via payments alone is extremely costly. In this situation, the use of replacement is efficient-despite its effect on increasing economic distortions-as it allows society to make smaller payments to the policymaker. This result effectively generalizes the endogenous turnover result of Ferejohn [37]

\footnotetext{
3 This is conditional on both the principal and the agent having the same discount factor. Note that in contrast to Acemoglu et al. [1-3], we cannot consider environments with capital accumulation or with private household information since this would significantly complicate our analysis.

For other examples of work which features backloading, see also Thomas and Worrall [59], and Ray [51].
} 
to an economy in which production is determined by optimizing households and where policymakers and citizens choose fully history dependent strategies associated with the most favorable equilibrium to the households. ${ }^{4}$

The final result of our paper is that our model generates a long run distribution of taxes, distortions, and turnover. In particular, we show that negative (positive) economic shocks which tighten (slacken) the government budget lead to a reduction (increase) in future taxes, investment, and tenure, where these all respond persistently to temporary economic shocks. Moreover, the model predicts that periods of possible turnover are associated with the lowest equilibrium taxes and the highest equilibrium investment distortions. Finally, these dynamics are associated with a probability of turnover which is a negative function of the tenure length of the incumbent. Note that these long run dynamics are significantly different relative to those in an environment with full information, since in such an environment, taxes are i.i.d., there are no distortions, and there is no turnover in the long run.

\section{Related literature}

Our paper is connected to several literatures. First, it is connected to a very large literature which studies the effect of political uncertainty on fiscal policy distortions. In this literature, the presence of political uncertainty leads policymakers to be short-sighted and to thus choose inefficient policies which lead to production distortions. ${ }^{5}$ Our main contribution to this literature is that we endogenize the level of political uncertainty by introducing asymmetric information. Thus, turnover risk-and therefore the horizon of the policymaker-is not exogenous, but is instead timevarying and a function of the entire history of economic shocks. This leads to the prediction that production distortions also respond persistently to economic shocks and are greatest following negative economic shocks during periods of turnover. ${ }^{6}$ By endogenizing political turnover, our paper is also very closely related to the literature on the political business cycle, and in particular to the work of Rogoff [52]. ${ }^{7} \mathrm{He}$ endogenizes political uncertainty in a three-period economy in which office-driven policymakers have private information about their competency, so that voting is prospective. In contrast to this work, we consider a setting in which policymakers are identical but have private information about the temporary state of the economy and their rent-seeking

\footnotetext{
4 Ferejohn [37] considers an environment in which a policymaker can only be punished or rewarded with replacement and in which citizens choose Markovian strategies. The presence of turnover in his environment does not require a sufficiently large variance in the private information of the policymaker, and this is because the model does not allow for endogenous production or distortions.

5 This theme emerges in a large body of work, which includes, but is by no means only limited to Persson and Svensson [47], Alesina and Tabellini [12], Alesina and Perotti [10], Krusell and Rios-Rull [42], Battaglini and Coate [19], Aguiar et al. [6], Caballero and Yared [24], Azzimonti [15], Aguiar and Amador [5] and Song et al. [55].

6 Technically, in our model, the limited commitment constraint on the policymaker can only bind following the realization of the lowest shock. This would not be the case in our model if there was full information but turnover was exogenous and i.i.d. (i.e., policymakers are less patient). In that case the limited commitment constraint could only bind following the realization of the highest shock, a feature which emerges in other work which assumes full information such as Aguiar et al. [6].

7 See Alesina [9] and Alesina et al. [11] as well as Drazen [32] for an overview of the political business cycle literature together with relevant references. In contrast to the majority of this work, we focus on the fiscal as opposed to the monetary channel for political distortions. Additionally, we consider a fully dynamic economy with retrospective voting so that the timing of turnover risk is completely endogenous and not exogenously determined by the timing of elections.
} 
activities, so that voting is retrospective. This facilitates characterization of the most favorable equilibrium for the households in a fully dynamic infinite horizon economy. ${ }^{8}$

Second, our paper is also related to the literature on retrospective voting, going back to the seminal work of Barro [17] and Ferejohn [37]. ${ }^{9}$ We contribute to this literature by characterizing the dynamics of turnover in a dynamic production economy with optimizing households in which citizens choose history-dependent non-Markovian strategies. This allows us to generalize the result of Ferejohn [37] by providing a sufficient condition under which turnover takes place.

Third, our analysis contributes to the large literatures on dynamic corporate finance, dynamic managerial compensation, and dynamic contracting and mechanism design. ${ }^{10}$ As in all of these literatures, our framework consists of a principal who uses transfers and retention policies to provide incentives to an agent. In the corporate finance literature, Quadrini [50] and Clementi and Hopenhayn [27] study the optimal contract between an investor and a risk neutral entrepreneur who can privately divert funds to himself and who privately observes the returns to his project. ${ }^{11}$ In these two papers, the entrepreneur faces two absorbing states: sufficiently many consecutive negative shocks lead to the liquidation of the project (akin to our government being replaced) and sufficiently many consecutive positive shocks lead to the full equity ownership of the project by the entrepreneur (the private information friction disappears and investment is undistorted from then on). Albuquerque and Hopenhayn [7] consider a similar environment to the previous two papers without private information but with limited commitment on the side of the entrepreneur. As in Ray [51] and Thomas and Worrall [60], there is no liquidation and distortions disappear in the long run. ${ }^{12}$

In the managerial compensation and turnover literature, Spear and Wang [56] consider retention policies in a repeated agency model, and they show that the manager also faces an absorbing state: he is replaced when either his continuation utility is sufficiently low or sufficiently high through "a golden parachute" (see also Sannikov [53]). Garrett and Pavan [39] study managerial turnover when the manager has privately observed productivity which follows a general process. ${ }^{13}$ Under imperfectly correlated shocks, they find that the optimal retention policy becomes more permissive over time, as information rents become more diluted.

Our key contribution with respect to these literatures is that we consider an environment with both limited commitment and private information on the side of a risk averse agent in a setting in which the principal can choose actions which affect the outside option of the agent. The ability to affect this outside option in the absence of private information leads to the backloading of incentives. Our introduction of private information to this framework implies that dynamic incentives are no longer only provided by backloading, but also by value spreading, a common feature of

\footnotetext{
8 As discussed in Rogoff [52], it is very difficult to analyze prospective voting in a fully dynamic environment.

9 See Banks and Sundaram [16], Persson and Tabellini [48], Besley [22], Egorov [33], and Fearon [36] for extensions.

10 For examples of models on dynamic contracting and dynamic mechanism design, see the work cited in Footnote 3 , as well as Thomas and Worrall [58], Atkeson and Lucas [14], Phelan [49], Athey and Bagwell [13], Levin [43], Farhi et al. [35], and Pavan et al. [46], among others.

11 See also DeMarzo and Fishman [30,31], and Biais et al. [23].

12 Additional contributions to the literature with one sided commitment and investment distortion include the classic work of Thomas and Worrall [59] and the more recent contributions of Aguiar and Amador [5] and Kovrijnykh [41].

13 See also Garrett and Pavan [38]. This paper abstracts from retention considerations and analyzes the optimal compensation contract for a risk-averse manager who is ex-ante privately informed about his productivity.
} 
an optimal contract whenever the agent has private information. ${ }^{14}$ Finally, the presence of risk aversion is critical in our framework since it generates a permanent need for risk-sharing between the principal and the agent, and this force generates long run distortions. ${ }^{15}$

This paper is organized as follows. Section 2 describes the model. Section 3 defines and provides a recursive representation for the equilibrium. Section 4 characterizes the benchmark cases with full information and full commitment. Section 5 summarizes our results once the frictions of limited commitment and asymmetric information are allowed to interact. Section 6 concludes. The Online Appendix includes proofs and additional material not included in the text.

\section{Model}

We describe an environment in which households choose a level of investment and policies are chosen by self-interested policymakers. Policymakers cannot commit to policies, have private information about the shocks to the government budget, and can privately rent-seek. In this environment, households discipline policymakers by threatening to remove them from power.

\subsection{Economic environment}

There are discrete time periods $t=\{0, \ldots, \infty\}$. In every period there is a stochastic state $\theta_{t} \in$ $\Theta \equiv\left\{\theta^{1}, \ldots, \theta^{N}\right\}$ with $\theta^{n}>\theta^{n-1} \geq 0$ and $N \geq 2$. The state is i.i.d. and occurs with probability $\pi\left(\theta_{t}\right)$. There is a continuum of mass 1 of identical households with the following utility:

$$
E_{0}\left(\sum_{t=0}^{\infty} \beta^{t} u\left(c_{t}\right)\right), \quad \beta \in(0,1),
$$

where $c_{t}$ is consumption and $\beta$ is the discount factor. $u(\cdot)$ is strictly increasing and strictly concave in $c_{t}$ with $\lim _{c \rightarrow 0} u^{\prime}(\cdot)=\infty$ and $\lim _{c \rightarrow \infty} u^{\prime}(\cdot)=0$. In addition $u\left(c_{t}\right)=-\infty$ for $c_{t}<0 .{ }^{16}$ Households enter every period with a fixed endowment $\omega>0$. They decide how much of this endowment to dedicate to investment $i_{t} \geq 0$ which produces output $y_{t}=f\left(i_{t}\right) . f(\cdot)$ is strictly increasing and strictly concave in $i_{t}$ with $f(0)=0, \lim _{i \rightarrow 0} f^{\prime}(\cdot)=\infty$ and $\lim _{i \rightarrow \infty} f^{\prime}(\cdot)=0 .{ }^{17}$ A household has the following per period budget constraint:

$$
c_{t}=\omega-i_{t}+y_{t}-\tau_{t}\left(y^{t}\right) \quad \forall t,
$$

where $\tau_{t}\left(y^{t}\right) \gtreqless 0$ represents the taxes incurred which can be a function of the entire history of output by the household $y^{t}$. We constrain taxes so that $\tau_{t}\left(y^{t}\right) \leq y_{t}$, meaning that the government cannot impose a tax on production which exceeds one hundred percent. Note that independently

\footnotetext{
14 Value spreading can often lead to immiseration of the agent in such framework, and this cannot occur in our environment since the worst punishment for the agent is not immiseration but replacement. In Section 5.1, we discuss in greater detail the connection of our results to the immiseration result.

$15 \mathrm{Li}$ and Matouschek [45] consider a related environment with backloading and value spreading and find the presence of long run distortion. However, in contrast to our work, their result is not driven by optimality considerations but by the non-existence of any equilibrium without long run distortions.

16 Our main results can also be generalized to an environment in which the household's utility function is well defined for any arbitrarily negative level of consumption.

17 Though we refer to $i_{t}$ as investment throughout for simplicity, it can be thought of as any intermediate input. For instance, without affecting any results, one can easily extend the model so that households face a consumption-leisure tradeoff with $i_{t}$ now corresponding to a labor input.
} 
of the level of taxes, a household can always guarantee itself a level of consumption of at least $\omega$ by choosing investment to equal 0 .

There is a continuum of potential and identical self-interested policymakers each indexed by $j \in J$. Let $P_{j t}=\{0,1\}$ be an indicator function which denotes whether a policymaker $j$ has power in period $t$ where $P_{j t}=1$ denotes that policymaker $j$ holds power. Only one policymaker holds power, so that if $P_{j t}=1$ then $P_{-j t}=0$ for $-j \neq j$. Policymaker $j$ has the following utility:

$$
E_{0}\left(\sum_{t=0}^{\infty} \beta^{t}\left(P_{j t} v\left(x_{t}\right)+\left(1-P_{j t}\right) \underline{V}(1-\beta)\right)\right),
$$

for $x_{t} \geq 0$ which represents rents paid to the policymaker in power and $\underline{V}(1-\beta) \leq v(0)$ which represents the exogenous flow utility to a policymaker who is not in power. $v(\cdot)$ is strictly increasing and strictly concave in $x_{t}$ with $\lim _{x \rightarrow 0} v^{\prime}(\cdot)=\infty$ and $\lim _{x \rightarrow \infty} v^{\prime}(\cdot)=0$.

The government has the following per period budget constraint:

$$
x_{t}=\tau_{t}\left(y^{t}\right)+\theta_{t}
$$

where we have taken into account that since households are identical, the government's aggregate tax revenue equals the individual tax burden $\tau_{t}\left(y^{t}\right) . \theta_{t}$ represents a government endowment which is determined after investment is undertaken and before policies $\tau_{t}\left(y^{t}\right)$ are chosen. It captures a shock to the cost of public spending or to the value of government royalties. The resource constraint of the economy implied by (2) and (4) is:

$$
c_{t}+x_{t}=\omega-i_{t}+f\left(i_{t}\right)+\theta_{t} .
$$

The most important feature of this setting is that while the entire society observes the policy $\tau_{t}\left(y^{t}\right)$, the values of $x_{t}$ and $\theta_{t}$ are privately observed by the policymaker in power. This means that citizens cannot distinguish between resources which are used to alleviate the government budget constraint from resources which are used for private rent-seeking by the policymaker.

\subsection{Political environment}

The political environment is as follows. At every date $t$, citizens decide whether or not to replace an incumbent. Formally, if $P_{j t-1}=1$, then if citizens choose $P_{j t}=1$ policymaker $j$ remains in power, and if citizens choose $P_{j t}=0$ a replacement policymaker $k \in J$ is randomly chosen to replace $j$ from the set $J$. To reduce notation, we let $P_{t}=\{0,1\}$ correspond to the decision of whether or not keep an incumbent at date $t .{ }^{18}$

Following the replacement decision, households make their investment $i_{t}$. Nature then draws $\theta_{t}$ which is privately observed by the policymaker. The policymaker then chooses policies $\left\{x_{t}, \tau_{t}\left(y^{t}\right)\right\}$ subject to (4) and subject to the constraint that $\tau_{t}\left(y^{t}\right) \leq y_{t}$. Note that a policymaker can always choose $\tau_{t}\left(y^{t}\right)=y_{t}$ after the household investment decision has been determined, implying from (5) that $c_{t}=\omega-i_{t}$. Note that $c_{t}$ may be negative off the equilibrium path, though this will never be the case along the equilibrium path given our assumption that $u\left(c_{t}\right)=-\infty$ for $c_{t}<0$. A key feature of this game is that even though citizens make their economic decisions

\footnotetext{
18 In our model, policymakers can only be in power once. Nonetheless, one can extend our analysis under some refinements so as to allow for the possibility of returning to power without altering any of our main results. Under this extension, $\underline{V}$ represents an endogenous value of being thrown out of power.
} 
independently, they make their political decisions regarding the replacement of the policymaker jointly. Since citizens are identical, there is no conflict of interest between them. These joint political decisions can be achieved by a variety of formal or informal procedures such as elections, protests, revolutions, or coups. We simplify the discussion by assuming that the decision is taken by the same single representative citizen in every period. ${ }^{19}$

There are two essential features of this game. First, the policymaker suffers from limited commitment within the period. Specifically, following the investment decision of households, the policymaker may decide to fully expropriate households and set rents equal to $f\left(i_{t}\right)+\theta_{t}$, which is the maximum. Thus, in a one-shot version of this model, households would anticipate full expropriation and would therefore not invest. Second, the policymaker privately observes the government budget shock and the total amount of rent-seeking. As such, if the shock $\theta_{t}$ is high so that the government budget is slack and taxes can be low, the policymaker may instead pretend that the government budget is tight so as to choose higher taxes and to privately rent-seek. ${ }^{20} \mathrm{In}$ the following section, we investigate how reputational considerations can alleviate the problem of limited commitment and asymmetric information in this environment.

\section{Equilibrium}

As in Chari and Kehoe [25,26] we consider sustainable equilibria. Individual households are anonymous and non-strategic in their private market behavior, though the representative citizen is strategic in his replacement decision. The policymaker in power is strategic in his choice of policies, and he must ensure that the government's budget constraint is satisfied given the resource constraint and the anonymous market behavior of households. Using this definition, we characterize the entire set of equilibria and we consider the conditions which are necessary for the most favorable equilibrium for households.

\subsection{Equilibrium}

We begin by defining strategies of the citizens and the policymaker. We introduce a publicly observed random variable to allow for correlated strategies. In every period, $z_{t} \in Z \equiv[0,1]$ is drawn from a uniform distribution. This publicly observed random variable allows the government to choose policies and the citizens to make replacement decisions as a function of the realization of the variable (i.e., citizens can probabilistically replace an incumbent). Technically, the presence of this public randomization device guarantees that the constraint set in the problem that we solve is convex.

Define $h_{t}^{0}=\left\{z^{t},\left\{P_{j}^{t-1}\right\}_{j \in J}, \rho^{t-1}\right\}$ as the history of the public random variable, replacement decisions, and policies after the realization of $z_{t}$, where $\rho_{t}$ corresponds to the vector of tax policies for each $y^{t}$ at date $t$. Let $h_{t}^{1}=\left\{h_{t}^{0},\left\{P_{j}^{t}\right\}_{j \in J}\right\}$ and let $h_{t}^{2}=\left\{h_{t}^{0},\left\{P_{j}^{t}\right\}_{j \in J}, \theta_{t}\right\}$, where $h_{t}^{2}$ is only observed by the incumbent policymaker. A representative citizen's replacement strategy $\Upsilon$ assigns a replacement decision for every $h_{t}^{0}$. A representative household's investment sequence $\Phi$ assigns a level of investment at every $h_{t}^{1}$. The incumbent policymaker's strategy $\Sigma$ assigns

\footnotetext{
19 This is identical to the decision being made via majoritarian elections with sincere voting.

20 Note that, in addition, the representative citizen cannot commit to a replacement rule. However, as we describe below, this inability to commit does not impose additional frictions in our framework.
} 
policies for every $h_{t}^{2}$. Let $\left.\Upsilon\right|_{h_{t}^{0}}$ represent the continuation strategy of the representative citizen at $h_{t}^{0}$ and define $\left.\Phi\right|_{h_{t}^{1}}$ and $\left.\Sigma\right|_{h_{t}^{2}}$ analogously. ${ }^{21}$

The representative citizen's replacement strategy $\Upsilon$ solves the representative citizen's problem if, at every $h_{t}^{0}$, the continuation strategy $\left.\Upsilon\right|_{h_{t}^{0}}$ maximizes household welfare given $\{\Phi, \Sigma\}$. A representative household's investment sequence $\Phi$ solves the representative household's problem if at every $h_{t}^{1}$, the continuation investment sequence $\left.\Phi\right|_{h_{t}^{1}}$ maximizes household welfare given $\{\Upsilon, \Sigma\}$ and given the household's budget constraint. The incumbent policymaker's strategy $\Sigma$ solves the incumbent policymaker's problem if, at every $h_{t}^{2}$, the continuation strategy $\left.\Sigma\right|_{h_{t}^{2}}$ maximizes the incumbent policymaker's welfare given $\{\Upsilon, \Phi\}$ and given the government's budget constraint and the maximum constraint on taxes. Note that because households are anonymous, public decisions are not conditioned on their allocation.

An equilibrium consists of $\{\Upsilon, \Phi, \Sigma\}$ for which $\Upsilon$ solves the representative citizen's problem, $\Phi$ solves the household's problem, and $\Sigma$ solves the incumbent policymaker's problem.

\subsection{Equilibrium allocations}

To characterize equilibrium, we first characterize the set of allocations supported by equilibrium strategies. Let $q_{t}=\left\{z_{0}, \ldots, z_{t-1}, \theta_{0}, \ldots, \theta_{t-1}\right\}$, the exogenous equilibrium history of public signals and states prior to the realization of $z_{t}$. With some abuse of notation, define an equilibrium allocation as a function of the exogenous history:

$$
\delta=\left\{P_{t}\left(q_{t}, z_{t}\right), i_{t}\left(q_{t}, z_{t}\right), c_{t}\left(q_{t}, z_{t}, \theta_{t}\right), x_{t}\left(q_{t}, z_{t}, \theta_{t}\right)\right\}_{t=0}^{\infty},
$$

where $P_{t}\left(q_{t}, z_{t}\right)$ is the value of $P_{t}$ chosen at $q_{t}, z_{t}$ and the other variables are defined analogously. Define

$$
\begin{aligned}
V_{t}\left(q_{t}\right)= & \int_{0}^{1}\left[\left(1-P_{t}\left(q_{t}, z_{t}\right)\right) \underline{V}\right. \\
& \left.+P_{t}\left(q_{t}, z_{t}\right)\left(\sum_{\theta_{t} \in \Theta} \pi\left(\theta_{t}\right)\left(v\left(x_{t}\left(q_{t}, z_{t}, \theta_{t}\right)\right)+\beta V_{t+1}\left(q_{t}, z_{t}, \theta_{t}\right)\right)\right)\right] d z_{t},
\end{aligned}
$$

the welfare expected by the incumbent at the beginning of the stage game prior to the realization of the public signal $z_{t}$. Moreover, define $J_{t}\left(q_{t}\right)$ analogously as the welfare of the households prior to the realization of $z_{t}$ :

$$
J_{t}\left(q_{t}\right)=\int_{0}^{1}\left[\sum_{\theta_{t} \in \Theta} \pi\left(\theta_{t}\right)\left(u\left(c_{t}\left(q_{t}, z_{t}, \theta_{t}\right)\right)+\beta J_{t+1}\left(q_{t}, z_{t}, \theta_{t}\right)\right)\right] d z_{t} .
$$

Finally, let $\mathcal{F}$ be the set of feasible allocations defined as follows. $\delta \in \mathcal{F}$ if and only if every element of $\delta$ at $\left\{q_{t}, z_{t}\right\}$ is measurable with respect to public information up to $t$ and for all $\left\{q_{t}, z_{t}, \theta_{t}\right\}, \delta$ satisfies the following constraints:

21 We are implicitly assuming that policymakers choose identical strategies independently of their identity. This assumption is without loss of generality since we focus on the most favorable equilibrium for the households. 


$$
\begin{aligned}
& P_{t}\left(q_{t}, z_{t}\right) \in\{0,1\}, i_{t}\left(q_{t}, z_{t}\right) \geq 0, c_{t}\left(q_{t}, z_{t}, \theta_{t}\right) \geq 0, x_{t}\left(q_{t}, z_{t}, \theta_{t}\right) \geq 0, \\
& c_{t}\left(q_{t}, z_{t}, \theta_{t}\right)+x_{t}\left(q_{t}, z_{t}, \theta_{t}\right)=\omega-i_{t}\left(q_{t}, z_{t}\right)+f\left(i_{t}\left(q_{t}, z_{t}\right)\right)+\theta_{t}, \quad \text { and } \\
& x_{t}\left(q_{t}, z_{t}, \theta_{t}\right) \leq f\left(i_{t}\left(q_{t}, z_{t}\right)\right)+\theta_{t} .
\end{aligned}
$$

The following proposition provides necessary and sufficient conditions for an allocation to be supported by equilibrium strategies.

Proposition 1 (equilibrium allocation). $\delta$ is supported by equilibrium strategies if and only if $\delta \in \mathcal{F}$ and $\forall q_{t}, z_{t}$

$$
\begin{aligned}
& v\left(x_{t}\left(q_{t}, z_{t}, \theta_{t}\right)\right)+\beta V_{t+1}\left(q_{t}, z_{t}, \theta_{t}\right) \\
& \quad \geq v\left(x_{t}\left(q_{t}, z_{t}, \widehat{\theta}\right)+\theta_{t}-\widehat{\theta}\right)+\beta V_{t+1}\left(q_{t}, z_{t}, \widehat{\theta}\right) \quad \forall \theta_{t}, \widehat{\theta} \in \Theta, \\
& v\left(x_{t}\left(q_{t}, z_{t}, \theta_{t}\right)\right)+\beta V_{t+1}\left(q_{t}, z_{t}, \theta_{t}\right) \\
& \quad \geq v\left(f\left(i_{t}\left(q_{t}, z_{t}\right)\right)+\theta_{t}\right)+\beta \underline{V} \quad \forall \theta_{t} \in \Theta, \quad \text { and } \\
& \sum_{\theta_{t} \in \Theta} \pi\left(\theta_{t}\right)\left(u\left(c_{t}\left(q_{t}, z_{t}, \theta_{t}\right)\right)+\beta J_{t+1}\left(q_{t}, z_{t}, \theta_{t}\right)\right) \geq u(\omega) /(1-\beta) .
\end{aligned}
$$

Proof. See Online Appendix.

The intuition for Proposition 1 is as follows. The government has significant flexibility in choosing its non-linear tax instrument $\tau_{t}\left(y^{t}\right)$. This effectively implies that as long as an allocation satisfies $\delta \in \mathcal{F}$ and (9), there exists a tax policy which implements the allocation. Intuitively, the government can effectively induce households to invest any amount as long as their expected consumption under the policy weakly exceeds that under 0 investment forever which yield $u(\omega) /(1-\beta)$. This explains why the constraint that $\delta \in \mathcal{F}$ and that (9) is satisfied is necessary and sufficient to guarantee optimality on the side of the households.

Constraints (AS-IC) (where AS stands for asymmetric information) and (C-IC) (where $C$ stands for commitment) capture the incentive compatibility constraints on the side of the policymaker. More specifically, constraint (AS-IC) captures the private information of the government. It guarantees that when the shock is $\theta_{t}$ the policy maker does not gain by pretending the shock is $\hat{\theta}_{t}$ and then implementing the policies designed for this latter type. Given (4), such an alternative policy provides him with rents equal to $x_{t}\left(q_{t}, z_{t}, \widehat{\theta}\right)+\theta_{t}-\widehat{\theta}$ at $t$ and a continuation value of $V_{t+1}\left(q_{t}, z_{t}, \widehat{\theta}\right)$ at $t+1$. Constraint (AS-IC) guarantees that he weakly prefers to choose the prescribed policy which provides him with rents equal to $x_{t}\left(q_{t}, z_{t}, \theta_{t}\right)$ at $t$ and a continuation value of $V_{t+1}\left(q_{t}, z_{t}, \theta_{t}\right)$ at $t+1$. Constraint (C-IC) captures the additional constraint coming from limited commitment. At any date $t$, the policymaker can engage in an observable deviation by expropriating all of the output of the economy. In this situation, this constraint guarantees that he prefers to pursue prescribed policies versus making this observable deviation and being thrown out of power which provides him with welfare $\underline{V}$ from tomorrow onward. ${ }^{22}$

A natural question emerges regarding the citizens' incentives to follow the prescribed replacement rules. Recall in our equilibrium definition that a representative citizen is strategic in his political behavior and therefore takes into account the impact of replacement on continuation equilibrium policies. Proposition 1 shows that satisfaction of such incentives does not place

22 As a reminder, $\underline{V} \leq v(0) /(1-\beta)$ so that there is no worse punishment than being thrown out of office. 
restrictions on the set of equilibrium allocations $\delta$. This is because it is trivial to construct a continuation equilibrium in the event of a deviation from the replacement rule which induces the representative citizen to not deviate. For instance, the continuation equilibrium off the equilibrium path can be chosen to be identical to the continuation equilibrium on the equilibrium path. ${ }^{23}$ In this case, citizens are always indifferent between keeping or replacing the current incumbent. Alternatively, the continuation equilibrium off the equilibrium path can be chosen to correspond to the repetition of the static Nash equilibrium with zero investment, which is costly for citizens. In this case, citizens always strictly prefer to pursue prescribed replacement rules. ${ }^{24,25}$

Let $\Lambda$ represent the set of allocations $\delta \in \mathcal{F}$ which satisfy conditions (AS-IC)-(9). We focus on the most favorable equilibrium for the households which is defined below.

Definition 1. The most favorable equilibrium for the households is the collection of allocations that solve the following program:

$$
\max _{\delta \in \Lambda} E_{0} \sum_{t=0}^{\infty} \beta^{t} u\left(c_{t}\left(q_{t}, z_{t}, \theta_{t}\right)\right) .
$$

The additional constraint that $\delta \in \Lambda$ ensures that the allocation satisfies the equilibrium necessary conditions. Note that this definition is analogous to that of Acemoglu et al. [1-3] since it ignores the welfare of the incumbent as well as all candidate policymakers.

\subsection{Recursive representation of equilibrium}

To facilitate the analysis, we provide a recursive formulation for (10). Define $\bar{J}$ as the utility attained under the solution to (10). Note that if the solution to (10) admits $P_{t}\left(q_{t}, z_{t}\right)=0$ for some $\left\{q_{t}, z_{t}\right\}$, then the welfare of households at $\left\{q_{t}, z_{t}\right\}$ is equal to $\bar{J}$. This is because if it were not the case, it would be possible to pursue the same sequence of allocations from $\left\{q_{t}, z_{t}\right\}$ onward as those starting from date 0 , and this would continue to satisfy all of the equilibrium constraints while strictly increasing the welfare of households. Therefore, whenever a policymaker is replaced, households receive their highest continuation value $\bar{J}$.

A natural question pertains to the continuation value that a policymaker receives in his first period in power. In principle, it is possible that (10) admits different levels of welfare for new incumbents even though households continue to receive $\bar{J}$. In this situation, we select the equilibrium which also maximizes the welfare of the policymaker subject to providing the households with their maximum welfare $\bar{J}$, where we denote this welfare by $V_{0}$. Therefore, the equilibrium resets whenever turnover occurs. ${ }^{26}$

\footnotetext{
23 In the most favorable equilibrium for the households, this would mean that efficiency is sustained even off the equilibrium path; it would not be possible to make either the representative citizen or the policymaker strictly better off without making the other player strictly worse off.

24 That is, unless citizens are receiving a welfare of $\omega /(1-\beta)$ along the equilibrium path, in which case they are indifferent. What is critical behind our argument is that candidate policymakers observe the history of the game and can therefore determine if citizens deviated from the equilibrium replacement rule.

25 Note that, by this rationale, our main results are also preserved if we allow for an exogenous cost for citizens of replacing incumbents, as long as this cost is sufficiently small.

26 This is consistent with the notion of constrained Pareto efficiency which we are using. In practice, the cases we consider will imply a unique $V_{0}$, so that this multiplicity is not an issue for any of the results in our paper.
} 
Let $J(V)$ correspond to the highest continuation value which the households receive at $t$ conditional on having promised the $t-1$ policymaker a continuation value $V$ starting from date $t$. Starting from a given $V$, let $\alpha$ correspond to

$$
\alpha=\left\{P(z) \in\{0,1\}, i(z) \geq 0,\left\{c(\theta, z) \geq 0, x(\theta, z) \geq 0, V^{+}(\theta, z)\right\}_{\theta \in \Theta}\right\}_{z \in[0,1]},
$$

where $P(z)$ is value of $P_{t}$ chosen if $z_{t}=z$, and $i(z), c(\theta, z)$, and $x(\theta, z)$ are analogously defined. Let $V^{+}(\theta, z)$ correspond to the continuation value starting from $t+1$ if $z_{t}=z$ and $\theta_{t}=\theta$. Moreover, let $\bar{V}$ correspond to the highest continuation value which can be provided to the incumbent policymaker in an equilibrium. The recursive program is:

$$
\begin{aligned}
J(V)= & \max _{\alpha}\left\{\int_{0}^{1}[(1-P(z)) \bar{J}\right. \\
& \left.\left.+P(z)\left(\sum_{\theta \in \Theta} \pi(\theta)\left(u(c(\theta, z))+\beta J\left(V^{+}(\theta, z)\right)\right)\right)\right] d z\right\}
\end{aligned}
$$

s.t.

$$
\begin{aligned}
& V=\int_{0}^{1}\left[(1-P(z)) \underline{V}+P(z)\left(\sum_{\theta \in \Theta} \pi(\theta)\left(v(x(\theta, z))+\beta V^{+}(\theta, z)\right)\right)\right] d z, \\
& c(\theta, z)+x(\theta, z)=\omega-i(z)+f(i(z))+\theta \quad \forall \theta, z, \\
& x(\theta, z) \leq f(i(z))+\theta \quad \forall \theta, z \\
& v(x(\theta, z))+\beta V^{+}(\theta, z) \geq v(x(\widehat{\theta}, z)+\theta-\widehat{\theta})+\beta V^{+}(\widehat{\theta}, z) \quad \forall \theta, \widehat{\theta}, z, \\
& v(x(\theta, z))+\beta V^{+}(\theta, z) \geq v(f(i(z))+\theta)+\beta \underline{V} \quad \forall \theta, z, \\
& \sum_{\theta \in \Theta} \pi(\theta)\left(u(c(\theta, z))+\beta J\left(V^{+}(\theta, z)\right) \geq u(\omega) /(1-\beta) \quad \forall z,\right. \\
& \text { and } V^{+}(\theta, z) \in[\underline{V}, \bar{V}] \quad \forall \theta, z .
\end{aligned}
$$

Program $P_{0}$ takes into account that if $P(z)=0$, the incumbent policymaker is replaced and households receive a continuation welfare $\bar{J}$. Otherwise, the incumbent is not replaced and the households receive consumption $c(\theta, z)$ today and a continuation value $J\left(V^{+}(\theta, z)\right)$ starting from tomorrow for each $\theta, z$. Constraint (12) is the promise-keeping constraint for the current incumbent which guarantees that his continuation value equals $V$. It takes into account that if he is replaced, he receives a continuation value $\underline{V}$. If he is not replaced, he receives consumption $x(\theta, z)$ today and a continuation value $V^{+}(\theta, z)$ starting from tomorrow for each $\theta, z$. Constraints (13)-(17) correspond to the recursive versions of constraints (7)-(9). Constraint (18) guarantees that the continuation value $V^{+}(\theta, z)$ is in the feasible range between $\underline{V}$ and $\bar{V}$.

In the Online Appendix, we prove technical results that are used for the characterization of the above problem. We establish that $J(V)$ is weakly concave in $V$ and that it is continuously differentiable in $V \in(\underline{V}, \bar{V})$. In addition, it has the following property: It satisfies $J(V)=\bar{J}$ for $V \in\left[\underline{V}, V_{0}\right]$ and it is strictly decreasing in $V$ if $V \in\left(V_{0}, \bar{V}\right]$ (where $V_{0}$ is the continuation value that a policymaker receives in his first period in power). That $J(V)$ is weakly decreasing follows from the fact that it must not be possible to make households strictly better off without making the incumbent weakly worse off, and this follows from the definition of the most favorable 
equilibrium for the households. If $V \in\left(\underline{V}, V_{0}\right)$, then the incumbent policymaker faces a positive probability of replacement, and in this situation households randomize between keeping the policymaker in power which provides him with $V_{0}$ or throwing the policymaker out of power which provides him with $\underline{V}$. In both of these circumstances, households receive a continuation welfare equal to $\bar{J}$ and the policymaker who is ultimately in power-whether it is last period's incumbent or a replacement policymaker-receives a continuation values of $V_{0}$ (conditional on $z$ ). Therefore, the welfare of households does not vary with $V$ in this range. These results imply that if $V \geq V_{0}$, there is no turnover $(P(z)=1) .^{27}$ The formal statement of these results is below.

Lemma 1. $J(V)$ satisfies the following properties: (i) It is weakly concave in $V$, and (ii) it satisfies $J(V)=\bar{J}$ for $V \in\left[\underline{V}, V_{0}\right]$ and is strictly decreasing in $V$ if $V \in\left(V_{0}, \bar{V}\right]$. In addition, the solution to program $P_{0}$ satisfies the following properties: (iii) If $V \geq V_{0}$, then $P(z)=1 \forall z$, and (iv) for $V \in\left(\underline{V}, V_{0}\right)$ there is a solution with $0<\int_{0}^{1} P(z) d z<1$.

\section{Proof. See Online Appendix.}

Before the equilibrium characterization, we find useful to make the following remarks. Let $i^{*}$ correspond to the solution to $f^{\prime}\left(i^{*}\right)=1$, in other words, the level of investment which equates the marginal benefit to the marginal cost of investment. Throughout the draft, we will refer to a situation in which $i_{t} \neq i^{*}$ as a distortion to production at $t$. It is straightforward to see that the equilibrium that maximizes households' welfare and ignores constraints (15) and (16) sets $i_{t}=i^{*}$ for all $t$, so that investment is efficient, and $x_{t}=0$ for all $t$, so that policymakers receive zero rents.

We make the following assumption regarding $\underline{V}$ to guarantee that constraints (15) and (16) bind in the most favorable equilibrium for the households.

Assumption 1 (political constraints matter). $\underline{V}$ satisfies

$$
\frac{v(0)}{1-\beta}<v\left(f\left(i^{*}\right)+\theta^{N}\right)+\beta \underline{V} .
$$

Assumption 1 guarantees that the equilibrium that maximizes households' welfare and ignores constraints (15) and (16) is not politically sustainable. To see why, note that the left hand side of (19), which is the welfare of receiving zero rents forever, corresponds to the highest possible continuation value to an incumbent in power under the best equilibrium for households. The right hand side of (19) corresponds to the welfare which the incumbent could achieve under the best equilibrium for households by taxing all of output under the highest level of $\theta_{t}$ and being punished by replacement immediately after. Assumption 1 implies that condition (16) is not satisfied under the equilibrium that maximizes households' welfare and ignores constraints (15) and (16), which means that these allocations cannot be supported as an equilibrium. Note that Assumption 1 is trivially satisfied if $v(0)=\underline{V}(1-\beta)$, so that the policymaker's value of being thrown out of office is no worse than that associated with receiving zero rents forever. ${ }^{28}$

\footnotetext{
27 In the Online Appendix we also show how the constraint set of the recursive problem can be simplified, and we prove that the value function is continuously differentiable.

28 As an aside, note that even if Assumption 1 were violated, we might have the case that the allocation arising from the equilibrium that maximizes households' welfare and ignores constraints (15) and (16) does not constitute an equilibrium since constraint (15) may be violated.
} 
A natural question of course regards the existence of an equilibrium with positive investment, since it is clear that in a one-shot version of our model that investment by households is zero since they expect the incumbent to tax them one hundred percent. We make the following assumption on the discount factor which guarantees the existence of such an equilibrium for the remainder of our analysis.

Assumption 2 (high enough discount factor). $\beta$ satisfies

$$
\begin{aligned}
& v\left(f\left(i^{*}\right)-i^{*}+\theta^{1}\right)+\beta \frac{\sum_{n=1}^{N} \pi\left(\theta^{n}\right) v\left(f\left(i^{*}\right)-i^{*}+\theta^{n}\right)}{1-\beta} \\
& \quad>v\left(f\left(i^{*}\right)+\theta^{1}\right)+\beta \underline{\underline{V} .}
\end{aligned}
$$

Under Assumption 2, there exists a simple stationary equilibrium in which the policymaker remains in power forever and chooses a constant tax which is independent of the shock and which leaves households indifferent between investing 0 and investing the efficient level $i^{*}$. The below lemma proves the existence of an equilibrium with positive investment, and we include the proof in the text since this example is useful in the discussion of equilibrium dynamics.

Lemma 2. Suppose Assumption 2 holds. Then an equilibrium with $P_{t}\left(q_{t}, z_{t}\right)=1$ and $i_{t}\left(q_{t}, z_{t}\right)=$ $i^{*}$ for all $\left(q_{t}, z_{t}\right)$, exists.

Proof. Define $\delta$ as follows. For all $\left(q_{t}, z_{t}\right)$, let $P_{t}\left(q_{t}, z_{t}\right)=1, i_{t}\left(q_{t}, z_{t}\right)=i^{*}, c_{t}\left(q_{t}, z_{t}, \theta_{t}\right)=\omega$, and $x_{t}\left(q_{t}, z_{t}, \theta_{t}\right)=f\left(i^{*}\right)-i^{*}+\theta_{t}$ for all $\theta_{t}$. The allocation satisfies (13), (14), and (17). It also implies that $V_{t}\left(q_{t}\right)=\sum_{\theta_{t} \in \Theta} \pi(\theta) v\left(f\left(i^{*}\right)-i^{*}+\theta_{t}\right) /(1-\beta)>v(0) /(1-\beta)$ for all $q_{t}$ and that $x_{t}\left(q_{t}, z_{t}, \theta_{t}\right)=x_{t}\left(q_{t}, z_{t}, \widehat{\theta}\right)+\theta_{t}-\widehat{\theta}$ for all $\left(q_{t}, z_{t}, \theta_{t}\right)$ and $\widehat{\theta}$. Therefore, (15) is satisfied. Moreover, by Assumption 2, (16) is satisfied if $\theta_{t}=\theta^{1}$. Given the concavity of $v(\cdot)$,

$$
\begin{aligned}
& v\left(f\left(i^{*}\right)+\theta^{n}\right)-v\left(f\left(i^{*}\right)-i^{*}+\theta^{n}\right) \\
& \quad<v\left(f\left(i^{*}\right)+\theta^{1}\right)-v\left(f\left(i^{*}\right)-i^{*}+\theta^{1}\right)
\end{aligned}
$$

for all $n>1$, which together with Assumption 2 implies that (16) is satisfied if $\theta_{t}=\theta^{n}$. Therefore, $\delta$ is supported by equilibrium strategies.

An important implication of Lemma 2 is that an equilibrium without economic or political cycles exists. This means that any distortions and turnover which occur in the most favorable equilibrium for the households must necessarily emerge as a consequence of optimality, and not because equilibria without distortions and turnover do not exists. For this reasons we maintain Assumption 2 throughout the rest of our draft. However, none of our main results depend on Assumption $2 .{ }^{29}$

The constraints (15) and (16) imply downward investment distortions. On the other hand the constraint on the maximum tax rate (14) implies an upward investment distortion when binding. For the remainder of the paper it is our goal to study the distortions implied by the political constraints; to do this, we assume that primitives are such that (14) does not bind along the equilibrium path.

29 More precisely, Proposition 2 holds without Assumption 2. Propositions 3 and 4 rely on conditions (24) and (25), respectively, and these conditions imply Assumption 2. 
Assumption 3. The solution to program $P_{0}$ is such that (14) is slack.

The above assumption implies that in the solution to program $P_{0}$, taxes are never equal to one hundred percent along the equilibrium path. This assumption is satisfied in the case in which at the endowment point returns to investment are greater than marginal cost so that $i^{*}>\omega$. In this case the government must choose negative taxes (i.e., making transfers to households) to prevent negative consumption of the household. When $i^{*} \leq \omega$ we have verified numerically that in many cases Assumption 3 holds. Finally if Assumption 3 were to be dropped it can be shown that the main result in Propositions 2 and 3 continue to hold. Throughout the rest of paper, we assume that Assumptions 1-3 hold.

\section{Benchmarks}

In this section, we highlight some features of the equilibrium under full information in which constraint (15) is ignored and we describe the equilibrium under full commitment in which constraint (16) is ignored. Analysis of these benchmarks allows us to highlight how our results are driven by the interaction of these two constraints.

\subsection{Full information benchmark}

We now consider the environment with full information, so that the citizens observe $\theta_{t}$ and $x_{t}$ and they can condition replacement decisions on the shock to the economy as well as the policies chosen by the policymaker. This corresponds to the solution to program $P_{1}$, where the latter is obtained from $\left(P_{0}\right)$ by dropping constraint (15). In this situation, all deviations by the policymaker from prescribed policies are observable and punished by replacement.

Before proceeding, it is useful to define $\bar{V}$, the highest equilibrium continuation value in the case of full information. Define $c^{\max }\left(\theta^{n}\right)$ and $x^{\max }\left(\theta^{n}\right)$ as the unique solution to

$$
\begin{aligned}
& \max _{\{c(\theta), x(\theta)\}_{\theta \in \Theta}} \sum_{\theta \in \Theta} \pi(\theta) v(x(\theta)) \\
& \text { s.t. } \quad c(\theta)+x(\theta)=\omega-i^{*}+f\left(i^{*}\right)+\theta \\
& \text { and } \quad \sum_{\theta \in \Theta} \pi(\theta) u(c(\theta)) \geq u(\omega) .
\end{aligned}
$$

It is clear by feasibility that

$$
\bar{V}(1-\beta) \leq \sum_{\theta \in \Theta} \pi(\theta) v\left(x^{\max }(\theta)\right) .
$$

The below lemma characterizes the dynamics of distortions to production in this economy.

Lemma 3 (full information). Suppose that:

$$
\begin{aligned}
& v\left(x^{\max }\left(\theta^{n}\right)\right)+\beta \frac{\sum_{l=1}^{N} \pi\left(\theta^{l}\right) v\left(x^{\max }\left(\theta^{l}\right)\right)}{1-\beta} \geq v\left(f\left(i^{*}\right)+\theta^{n}\right)+\beta \underline{V} \quad \forall n \\
& \text { and } c^{\max }\left(\theta^{1}\right)>\omega-i^{*} .
\end{aligned}
$$

Then under full information, the equilibrium that maximizes households' welfare has the following properties: 
1. Distortions emerge along the equilibrium path so that $i_{t}<i^{*}$ for some $t$, and

2. Distortions vanish in the long run so that

$$
\operatorname{Pr}\left\{\lim _{t \rightarrow \infty} i_{t}=i^{*}\right\}=1 \text {. }
$$

Proof. See Online Appendix.

Condition (21) implies that the repetition of the allocation associated with $c^{\max }\left(\theta^{n}\right)$ and $x^{\max }\left(\theta^{n}\right)$ satisfies the equilibrium constraints and the maximum tax constraints in the case of full information and provides the highest equilibrium continuation value to the policymaker. This condition is isomorphic to an assumption commonly made in similar models in which there is full information. ${ }^{30}$

The intuition for the first part of the lemma is that distortions emerge along the equilibrium path in order to limit the resources which the policymaker can expropriate from households. This relaxes the limited commitment constraint (16) and allows society to pay lower rents to the policymaker. Formally, suppose it were the case that in the initial date, $i_{0}=i^{*}$ and suppose for simplicity that $x_{0}>0$ for all $\left(\theta_{0}, z_{0}\right)$. In this situation, households could be made strictly better off by altering the allocation in a means which reduces the incumbent's welfare and strictly increases their welfare. Specifically, households can reduce their investment by $\epsilon>0$ arbitrarily small, where this is achieved by making the tax system distortionary. This perturbation relaxes the right hand side of (16) by approximately $\epsilon v^{\prime}\left(f\left(i^{*}\right)+\theta_{0}\right) f^{\prime}\left(i^{*}\right)$. This allows for the reduction of rents to the policymaker under each shock $\theta_{0}$ by approximately $\epsilon v^{\prime}\left(f\left(i^{*}\right)+\theta_{0}\right) f^{\prime}\left(i^{*}\right) / v^{\prime}\left(x_{0}\right)$ so as to preserve (16). Household consumption conditional on $\left(\theta_{0}, z_{0}\right)$ changes by approximately

$$
-\left(f^{\prime}\left(i^{*}\right)-1\right) \epsilon+\epsilon v^{\prime}\left(f\left(i^{*}\right)+\theta_{0}\right) f^{\prime}\left(i^{*}\right) / v^{\prime}\left(x_{0}\right)
$$

which exceeds 0 since $f^{\prime}\left(i^{*}\right)=1$. Therefore, distortions can make households strictly better off in the initial period.

The intuition for the second part of the lemma follows from the fact that backloading is optimal. Society optimally pays the policymaker more and more along the equilibrium path, and this is because this relaxes his limited commitment constraint (16) in the present as well as in the future. As such, even though distortions to production are efficient in the short term, in the long term they are inefficient since the policymaker is paid sufficiently that (16) is relaxed to the point that households can choose the efficient level of investment without being expropriated. Note that the absence of long run distortions under full information is not unique to our model, but common across a large class of full information principal-agent environments in which the agent suffers from limited commitment, as in Acemoglu et al. [1-3], for example.

\subsection{Full commitment benchmark}

We now consider the environment with full commitment. Households do not observe $\theta_{t}$ and $x_{t}$, so that they can only condition their replacement decision based on their observation of policy. Nonetheless, the policymaker is constrained in his choice of policies, since his only possible deviations include choosing policies associated with some alternative shock $\widehat{\theta} \neq \theta_{t}$. In other words, full expropriation is not feasible. As such, the full commitment benchmark corresponds to the solution to program $P_{2}$, where the latter is obtained from $P_{0}$ by dropping constraint (16).

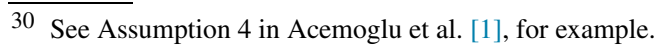


Lemma 4 (full commitment). Under full commitment, the equilibrium that maximizes households' welfare features no distortions along the equilibrium path or in the long run so that $i_{t}=i^{*}$ $\forall t$.

Proof. See Online Appendix.

The intuition for this lemma is that in the presence of full commitment, the policymaker has limited discretion over taxes. Moreover, his continuation payoff from choosing different levels of taxes is independent of the current and future level of investment. Therefore, distortions to production cannot facilitate incentive provision, and they therefore never appear. Formally, suppose it were the case that $i_{t} \neq i^{*}$. Then it would be possible to instead perturb the solution by setting $\widehat{i_{t}}=i_{t}^{*}$ and $\widehat{c_{t}}=c_{t}+f\left(i^{*}\right)-i^{*}-f\left(i_{t}\right)+i_{t}$ and without altering any other portion of the contract. This perturbation would continue to be an equilibrium and would strictly increase household welfare.

\section{Analysis}

We now consider the equilibrium in an environment in which the presence of limited commitment and asymmetric information interact. In light of Lemmas 3 and 4, we show in Section 5.1 that long run distortions to production emerge in this setting. In Section 5.2, we present sufficient conditions for long run turnover, and in Section 5.3, we characterize long run dynamics.

\subsection{Long run distortions to production}

The main result of our paper is expressed in the below proposition. The proposition states that distortions emerge and never disappear, even in the long run. This result is in stark contrast to that in Lemmas 3 and 4, and it highlights the fact that distortions emerge as a consequence of the joint interaction of the limited commitment and the asymmetric information frictions.

Proposition 2 (long run distortions). The most favorable equilibrium for the households has the following properties:

1. Distortions emerge along the equilibrium path so that $i_{t}<i^{*}$ for some $t$, and

2. Distortions never vanish in the long run so that

$$
\operatorname{Pr}\left\{\lim _{t \rightarrow \infty} i_{t}=i^{*}\right\}=0 .
$$

Proof. See Online Appendix.

The first part of the proposition states that distortions must emerge, and the reasoning follows from similar arguments to those made in the full information benchmark of Section 4.1. Specifically, during an incumbent's first period of power (i.e., if $V=V_{0}$ ), the limited commitment constraint (16) binds, and there are distortions to production since these distortions relax (16).

The second part of the proposition states that distortions never disappear, even in the long run. The proof of this result is by contradiction. Suppose that in the long run, investment equals $i^{*}$, so that the commitment constraint (16) is slack, as in the case of full information. Based on the first part of the proposition, this would require that the continuation value in the long run strictly 
exceeds $V_{0}$, since at $V=V_{0}$, (16) binds and investment is distorted. The main arguments of the contradiction proof rest on the fact that, if the continuation value $V$ exceeds $V_{0}$ forever, then $V$ must converge in the long run; however, long run convergence in $V$ is not favorable for the households.

To get a sense of why $V$ would have to converge in the long run, consider the first order condition with respect to $V^{+}(\theta, z)$ together with the Envelope condition for $V>V_{0}$, where we take into account that $P(z)=1 \forall z$ for $V>V_{0}$ from Lemma 1:

$$
J^{\prime}(V) \leq \int_{0}^{1} \sum_{\theta \in \Theta} \pi(\theta) J^{\prime}\left(V^{+}(\theta, z)\right) d z
$$

From (22), the shadow marginal cost of providing a continuation value to the incumbent is a martingale. Intuitively, the continuation value in the future must weakly rise if $\theta_{t}$ is high as a reward for the policymaker, and it must weakly fall if $\theta_{t}$ is low as a punishment for the policymaker. Since $J^{\prime}(V)$ is a submartingale and it is bounded from above by zero, it must converge. If we suppose for simplicity that $J(V)$ is strictly concave, then this also implies that the value of $V$ must converge. This establishes that if there are no long run distortions, then the continuation value must converge.

To get a sense of why long run convergence in $V$ is not favorable for the households, suppose that it were the case that $V$ converged, with investment undistorted at $i^{*}$ and a relaxed commitment constraint (16). Satisfaction of the truth-telling constraints (15) in this case would require that $x(\theta, z)=x(\widehat{\theta}, z)+\theta-\widehat{\theta} \forall \theta, \widehat{\theta}, z$, so that from (4), taxes are constant and equal to some amount $\bar{\tau}$ in the long run. This means that whereas households consume a constant amount $\omega-i^{*}+f\left(i^{*}\right)-\bar{\tau}$, the policymaker (who remains in power forever since $V>V_{0}$ ) consumes a volatile amount $\bar{\tau}+\theta$, thus bearing all the risk in the economy. One can show that such an allocation is strictly dominated by one in which taxes respond to $\theta$, and both the households and the policymaker share the risk. Such an allocation provides dynamic incentives for the policymaker to choose lower taxes when $\theta$ is high, and it is more favorable to the households.

To illustrate the argument, suppose there are two shocks $\theta^{1}$ and $\theta^{2}$ with $\theta^{1}<\theta^{2}$ which occur with probability $1 / 2$. Consider the following perturbation from this stationary equilibrium starting from some date $t$. Suppose that the policymaker's consumption is increased by $\epsilon>0$ arbitrarily small at date $t$ if state 1 occurs at date $t$. Moreover, suppose that the policymaker's consumption is reduced by $.5\left(v^{\prime}\left(\bar{\tau}+\theta^{1}\right) / v^{\prime}\left(\bar{\tau}+\theta^{2}\right)-1\right) \epsilon$ at date $t$ if state 2 occurs at date $t$. Finally, suppose that the policymaker's consumption is reduced by $((1-\beta) / \beta) \epsilon$ at all dates and all states $t+k$ for $k \geq 1$ if state 1 occurs at date $t$. The policymaker's consumption at all dates $t+k$ for $k \geq 1$ if state 2 occurs at date $t$ is unchanged. It can be verified that the proposed perturbation provides the same continuation value to the policymaker and continues to satisfy incentive compatibility. Moreover, the expected change in household welfare equals

$$
\frac{u^{\prime}\left(\omega-i^{*}+f\left(i^{*}\right)-\bar{\tau}\right)}{2}\left(\frac{v^{\prime}\left(\bar{\tau}+\theta^{1}\right)}{v^{\prime}\left(\bar{\tau}+\theta^{2}\right)}-1\right) \epsilon>0,
$$

which is strictly positive given the strict concavity of $v(\cdot)$. In other words, the cost to households of a decrease in consumption at date $t$ if state 1 occurs at $t$ is perfectly outweighed by the benefit to households of an increase in consumption at all dates $t+k$ for $k \geq 1$ if state 1 occurs at $t$. This means that the change in household welfare equals the increase in consumption at date $t$ if state 2 occurs at date $t$. Therefore, convergence to a fixed $V$ is not favorable to the households. 
Thus, a perturbation in policies which shares risk with the households and which provides dynamic incentives to not privately rent-seek strictly increases the welfare of households. The argument relies crucially on the risk aversion on the side of the policymaker. If it were the case for example that the policymaker were risk neutral, then the term inside (23) would be equal to zero, so that there is no benefit to the perturbation and convergence to a stationary allocation without distortions would be optimal (the role of risk aversion in generating long run distortions has also been emphasized in Garrett and Pavan [38] where a similar result is obtained).

The broader intuition for the second part of Proposition 2 is that a policymaker is always provided with dynamic incentives to not privately rent-seek, even in the long run. If $\theta_{t}$ is low (high) so that shock tightens (slackens) the budget constraint and observed taxes are high (low), then the policymaker is punished (rewarded) in the future with lower (higher) payment. This ensures that the policymaker does not privately rent-seek. Eventually a long sequence of negative shocks push payments to the policymaker sufficiently down that the policymaker becomes tempted to fully expropriate the investment of households. Anticipating this threat, households invest less, so that distortions to production eventually emerge as a means of preventing full expropriation.

There are three important points to keep in mind in interpreting the result behind Proposition 2. First, the presence of distortions in the long run does not emerge as a consequence of the non-existence of equilibria without distortions. As Lemma 2 makes clear, such equilibria exist, but Proposition 2 states that they are not optimal for the households.

Second, Proposition 2 holds for any arbitrarily small variance in the private information of the policymaker. Suppose for example that $\theta_{t}=\left\{\theta^{*}-\sigma, \theta^{*}+\sigma\right\}$ for some $\theta^{*}>\sigma>0$, where each state occurs with probability $1 / 2$. In this circumstance, distortions persist in the long run even for $\sigma$ arbitrarily close to 0 . Nevertheless, if $\sigma=0$, then households can effectively deduce the level of rent-seeking by observation of their own consumption, so that Lemma 3 applies and distortions vanish in the long run. Therefore, the introduction of any arbitrarily small amount of privately observed uncertainty to the full information benchmark leads to the presence of long run distortions. In the most favorable equilibrium for the households these distortions vanish as uncertainty goes to zero.

Finally, the reasoning behind this proposition relies in part on the presence of a participation constraint on the side of the households captured by (17). In the absence (17), one could construct a stationary allocation in which households consume zero and the policymaker consumes rents equal to $\omega-i^{*}+f\left(i^{*}\right)+\theta_{t}$ in every period. Under such an allocation, it would not be possible to perturb the equilibrium so as to induce more risk sharing between the policymaker and the households since household consumption cannot decline.

This final point elucidates the connection behind our result and that of Thomas and Worrall [58] and Atkeson and Lucas [14] who show that in a model of consumption risk sharing with private information, the agent's utility always declines to a minimum level. Their environment is isomorphic to our environment if constraints (14), (16), and (17) are ignored; if the households are risk-neutral; and if replacement is not allowed. As in our environment, they find that the agent's continuation value never converges to a maximal stationary level. Nonetheless, the reasoning for their result is different from ours. In our environment, this is true because even though the agent's welfare reaches the maximal level $\bar{V}$ along the equilibrium path, it must decline below $\bar{V}$ with positive probability, and this follows from optimal risk sharing. In their environment, the maximal level $\bar{V}$ is an absorbing state-much like it would be in our environment if constraint (17) were ignored-however the equilibrium never converges to such a state and this is a consequence of the Inada conditions on preferences. 


\subsection{Long run turnover}

In this section, we consider the dynamics of political turnover.

Proposition 3 (long run turnover). If the set of shocks $\Theta \equiv\left\{\theta^{1}, \ldots, \theta^{N}\right\}$ is such that

$$
v(0)+\beta \frac{\sum_{n=1}^{N} \pi\left(\theta^{n}\right) v\left(\theta-\theta^{1}\right)}{1-\beta}>v\left(f\left(i^{*}\right)+\theta^{1}\right)+\beta \underline{V},
$$

then the most favorable equilibrium for the households features long run turnover so that

$$
\operatorname{Pr}\left\{\lim _{t \rightarrow \infty} P_{t}=1\right\}=0 .
$$

Proof. See Online Appendix.

This proposition states that if condition (24) holds, which is always true if the variance of private information is sufficiently large, then there is political turnover both along the equilibrium path and in the long run. In other words, a permanent dictator never emerges. This is because, if the variance of private information is large, then the policymaker has high private rent-seeking opportunities, and replacement is a useful means of preventing private rent-seeking.

Specifically, society has two tools for providing incentives to policymakers to not privately rent-seek. On the one hand, society can directly pay higher future rents to reward a policymaker who chooses low taxes today. Though this costs societal resources, it reduces the policymaker's incentives to fully expropriate households since he values preserving power, and it allows households to choose the efficient level of investment today. On the other hand, society can instead punish policymakers who choose high taxes by removing them from office in the future. This does not cost any societal resources directly, but it raises a policymaker's incentives to fully expropriate households today since the horizon of the policymaker is reduced. In response, households are forced to invest less today, causing economic distortions. If the variance of private information is large, then a policymaker has high private rent-seeking opportunities, and providing incentives to the policymaker via payments alone is extremely costly. In this situation, the use of replacement is efficient-despite its effect on increasing economic distortions-as it allows society to make smaller payments to the policymaker.

The heuristic proof of this argument is as follows. Suppose it were the case that a permanent dictator emerged in equilibrium. Since a permanent dictator can always privately choose the policies associated with $\theta_{t}=\theta^{1}$, the informational constraints in (15) imply that the continuation welfare of such a policymaker conditional on $\theta_{t}=\theta^{1}$ must weakly exceed the left hand side of (24). Since this continuation value strictly exceeds the right hand side of (24), this implies that the limited commitment constraint (16) never binds under $\theta_{t}=\theta^{1}$. One can easily show that if this is the case, then the concavity of $v(\cdot)$ together with (15) guarantees that this constraint never binds under any $\theta_{t}$. Then, (16) is always slack under such a permanent dictator. However, if this is the case, there are no long run distortions, so that $\operatorname{Pr}\left\{\lim _{t \rightarrow \infty} i_{t}=i^{*}\right\}>0$, violating Proposition 2. Conceptually, whenever the constraint in (16) is slack, it implies that the continuation value to the incumbent must decline with positive probability, where this follows from (22) and the arguments in the previous section. These declines in continuation value can entail a reduction in rents. However, there is a limit to which these reductions can reduce welfare since $v(0)$, the minimum flow payoff from rents, is bounded from below by $\underline{V}(1-\beta)$, the flow payoff from being thrown out of power. For this reason, turnover must eventually be used in providing incentives. 
Note that this result effectively generalizes the endogenous turnover result of Ferejohn [37] to an economy in which production is determined by optimizing households and where policymakers and citizens choose fully history dependent strategies associated with the most favorable equilibrium for the households. Ferejohn [37] considers an environment in which a policymaker can only be punished or rewarded with replacement and in which citizens choose Markovian strategies. The presence of turnover in his environment does not require a sufficiently large variance in the private information of the policymaker, and this is because the model does not allow for endogenous production or distortions.

More specifically, the full commitment benchmark of Section 4.2 is isomorphic to an economy with exogenous production since the limited commitment constraint (16) is ignored. In such an economy, long run turnover occurs for any arbitrarily small variance in the private information of the policymaker. What Proposition 3 makes clear is that long run turnover requires this variance to be sufficiently large once the limited commitment constraint (16) is taken into account. This is because if the variance of private information is too small, then replacement is too costly for society in terms of the economic distortions it entails to be used in equilibrium.

\subsection{Long run dynamics}

In this section we explore the transitional dynamics in our model. Propositions 2 shows that the model produces long run distortions and Proposition 3 shows that it produces long run turnover if the variance of shocks is sufficiently high. The below proposition shows that the model also produces long run dynamics in investment and policies. Note that since policies determine rents through (4), and these can vary with respect to the shock $\theta_{t}$, we let $x_{t}(\theta)$ correspond to the value of rents at $t$ conditional on the realization of the shock $\theta_{t}=\theta$. It is clear that if there are long run dynamics in $x_{t}(\theta)$, then there are also long run dynamics in policies.

Proposition 4 (long run dynamics). If $N=2$ or if $N>2$ and $\beta$ is sufficiently high so as to satisfy

$$
\frac{\sum_{n=1}^{N} \pi\left(\theta^{n}\right) v\left(f\left(i^{*}\right)-i^{*}+\theta^{n}\right)}{1-\beta}>v\left(f\left(i^{*}\right)+\theta^{1}\right)+\beta \underline{V}+\Gamma
$$

for

$$
\Gamma=\sum_{n=2}^{N}\left(\sum_{l=2}^{N} \pi\left(\theta^{l}\right)\right)\left(v\left(f\left(i^{*}\right)+\theta^{1}+\theta^{n}-\theta^{n-1}\right)-v\left(f\left(i^{*}\right)+\theta^{1}\right)\right)
$$

then in the most favorable equilibrium for the households investment and taxes do not converge so that

$$
\begin{aligned}
& \operatorname{Pr}\left\{\lim _{t \rightarrow \infty} i_{t}=\widehat{i}\right\}=0 \quad \widehat{\forall i} \quad \text { and } \\
& \operatorname{Pr}\left\{\lim _{t \rightarrow \infty} x_{t}(\theta)=\widehat{x}(\theta)\right\}=0 \quad \forall \theta \quad \text { and } \quad \forall \widehat{x}(\theta) .
\end{aligned}
$$

Proof. See Online Appendix. 


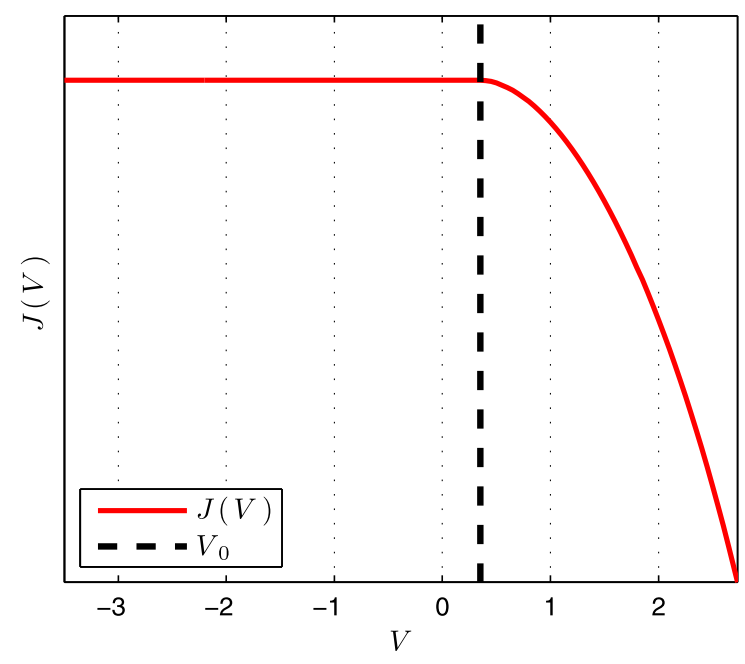

Fig. 1. Value function $J(V)$. Solution to $P_{0}$.

Proposition 4 states that if $N=2$ or if $N>2$ but the discount factor is sufficiently large so as to satisfy (25), then there are long run dynamics in investment and rents. ${ }^{31}$ Proposition 4 is a direct result of the fact that dynamic incentives are always provided in the long run. What Proposition 4 implies is that there is history-dependence in the sequence of investment and policies. In other words, even though shocks are i.i.d., investment and policies respond persistently to shocks. Note that these long run dynamics are significantly different relative to those in an environment with full information, since in such an environment, rents are i.i.d. and there are no distortions in the long run.

In order to further investigate the long run dynamics of our model, we perform a numerical simulation. Note that because the constraint set represented by (12)-(18) is not necessarily convex (conditional on $z$ ), a complete analytical characterization of equilibrium dynamics is not possible, and for this reason, we appeal to a numerical exercise to describe these long run dynamics. This exercise helps to provide additional intuition for the results of the previous section and also makes additional predictions. In our simulation, we consider the following functional forms

$$
u(c)=c^{.5} ; \quad v(x)=x^{.5} ; \quad f(i)=(1.5) i^{.8}
$$

and the following parameters:

$$
\beta=.5 ; \quad \omega=2.5 ; \quad \theta^{1}=1.0 ; \quad \theta^{2}=1.5 ; \quad \underline{V}=-3.5 .
$$

Fig. 1 depicts the welfare of households, $J(V)$, as a function of the welfare of the incumbent policymaker, $V$. As discussed in Section 3.3, as $V$ increases, $J(V)$ weakly decreases and this is because the policymaker acquires higher rents, which reduces the consumption of households. In addition, note that $J(V)$ is constant for $V \in\left[\underline{V}, V_{0}\right]$. In this region, the incumbent policymaker faces a positive probability of replacement, and in this situation households randomize between

\footnotetext{
31 Note that condition (25) is implied by Assumption 2 if $N=2$. The condition guarantees that the solution admits $i(z)=i^{*}$ if $V=\bar{V}$ so that there are no distortions whenever the continuation value approaches $\bar{V}$.
} 

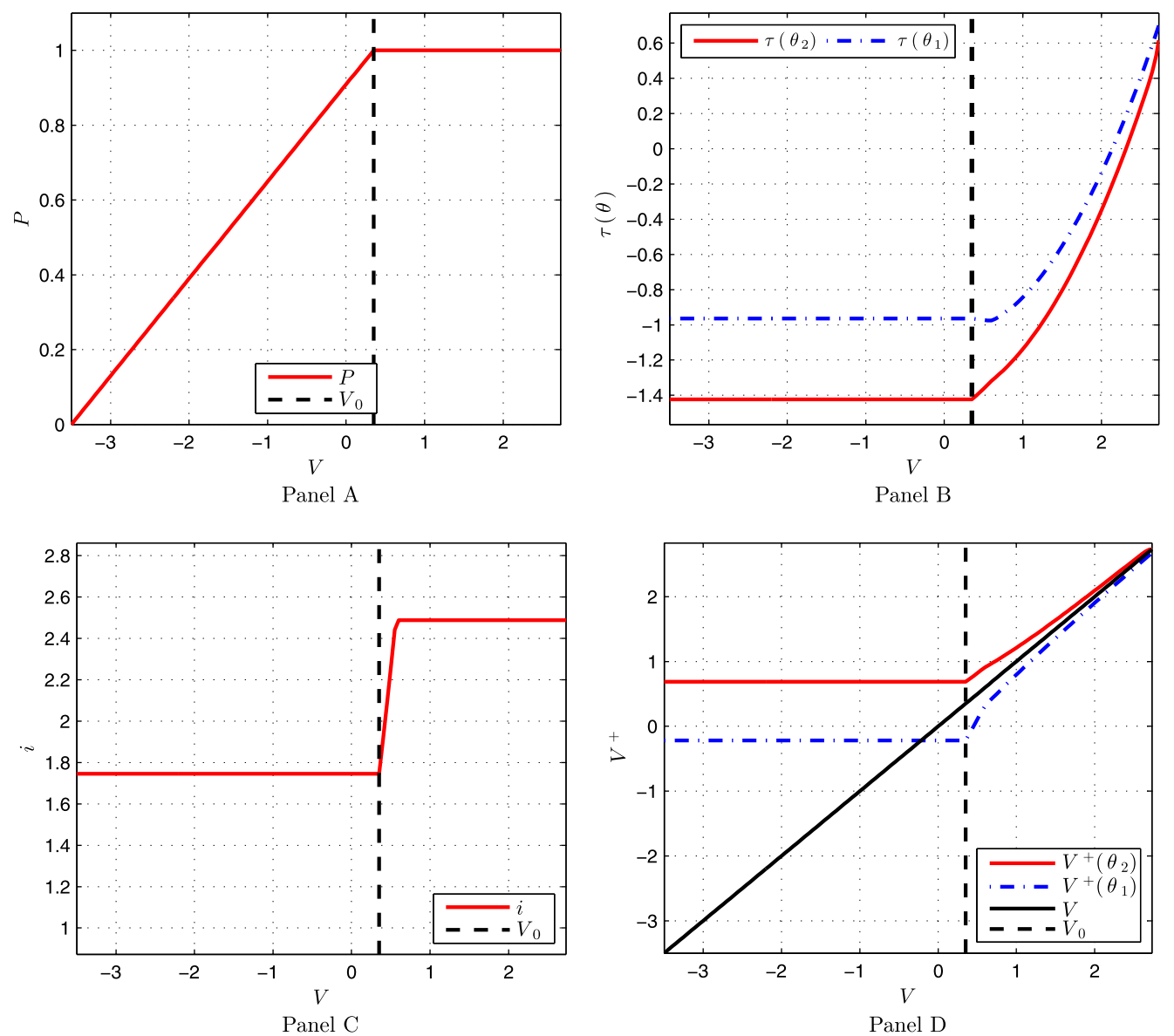

Fig. 2. Optimal policy functions $P, \tau, i$, and $V^{+}$. Solution to $P_{0}$ as a function of household promised utility $V . \tau$ derived from $x$ following (4).

keeping the policymaker in power which provides him with $V_{0}$ or throwing the policymaker out of power which provides him with $\underline{V}$. In both of these circumstances, households receive the same continuation welfare-whether it is last period's incumbent or a replacement policymaker.

Fig. 2 depicts the policy functions conditional on the state variable $V$, the continuation value promised to the policymaker. Panel A depicts the retention probability as a function of the incumbent's continuation value. It shows that an incumbent policymaker is only replaced if his promised continuation value is between $\underline{V}$, the value of being thrown out of power, and $V_{0}$ the value provided to an incumbent in his first period of power, where this probability of replacement increases as $V$ declines in this region. The intuition for this is that it is only efficient for households to replace a policymaker if his promised value is sufficiently low since replacement serves as a punishment for the policymaker.

Panel B depicts the level of taxes as a function of the continuation value. As a reminder, note that higher taxes corresponds to higher political rents and lower household consumption. Note that the policymaker and the households share risk: both consume more during the high shock and both consume less during the low shock, and taxes are lower during the high shock and 
higher during the low shock. As the continuation value to the incumbent rises, taxes rise since his rents under both the high and low shock also rise. Moreover, as the continuation value and the rents to the incumbent rise, taxes also become less volatile; this follows from the fact that it is efficient for the policymaker to bear a greater portion of the endowment shock risk since his consumption is higher. ${ }^{32}$

Panel $\mathrm{C}$ depicts the level of investment as a function of the continuation value. It shows that distortions emerge only if the continuation value is low (i.e., the level of investment is depressed below the efficient level only if the policymaker's welfare is low). The reason behind this is that if the policymaker's welfare is low, then the value he places on remaining in power is low. Therefore it is difficult to provide him with incentives to not fully expropriate households, and for this reason, investment must be low so as to reduce the number of resources under his control and to reduce his temptation to expropriate. As his continuation value rises, it becomes possible for households to invest closer to the efficient amount while continuing to satisfy the incentive compatibility constraints on the policymaker. Panel D shows how the policymaker is induced to choose the appropriate level of taxes and to not private rent-seek. It depicts the continuation value in the future as a function of the continuation value today. It shows that if the high shock occurs today, the policymaker is rewarded in the future with an increase in continuation value whereas if the low shock occurs today, the policymaker is punished in the future with a decrease in continuation value. ${ }^{33}$

These figures provide a graphical representation for the long run dynamics of our model. If a policymaker experiences a negative economic shock, his continuation value declines, and if he experiences a positive economic shock, his continuation value increases. These dynamic incentives induce the policymaker to not privately rent-seek. Note that a decline in continuation value implies a weakly lower investment, weakly lower taxes and rents, and weakly shorter tenure. In contrast, a positive economic shock can be followed by weakly higher investment, weakly higher taxes and rents, and weakly longer tenure. These dynamics exhibit history-dependence since investment, taxes, and turnover depend on the entire history of shocks through the implied continuation value to the incumbent. Note that if a policymaker experiences a long enough sequence of low shocks, he is necessarily replaced with some probability. Importantly, periods of potential turnover are periods in which taxes are lowest (and actually negative in the simulation) and investment distortions are the highest.

We additionally consider what our model implies regarding the relationship between the turnover rate and the tenure length of policymakers. Fig. 3 depicts the Kaplan-Meier estimate of the probability of replacement as a function of the tenure length of the incumbent. The figure displays the smoothed hazard function using a rectangular smoothing kernel. The relationship is negative. In other words, policymakers with very short tenure are the most likely to be thrown out of power. The economic reasoning is as follows. A young incumbent is likely to have a low continuation value and be likely to be unlucky and be thrown out of power. In contrast, an older incumbent, who has lasted for several periods, is likely to have experienced many positive shocks and is thus more likely to have a high continuation value and be forgiven by citizens following a

\footnotetext{
32 The policies depicted in Panels B, C, and D for continuation values to the left of $V_{0}$ take into account that in equilibrium the value of these policies is independent of whether or not the incumbent is replaced or retained.

33 Note that while the continuation welfare of households is maximized during periods of turnover, this result is altered if one extends the model to allow for an exogenous cost for citizens of replacing incumbents. In this situation, after a sufficient number of negative shocks, household welfare begins to decline as the prospect of turnover approaches.
} 


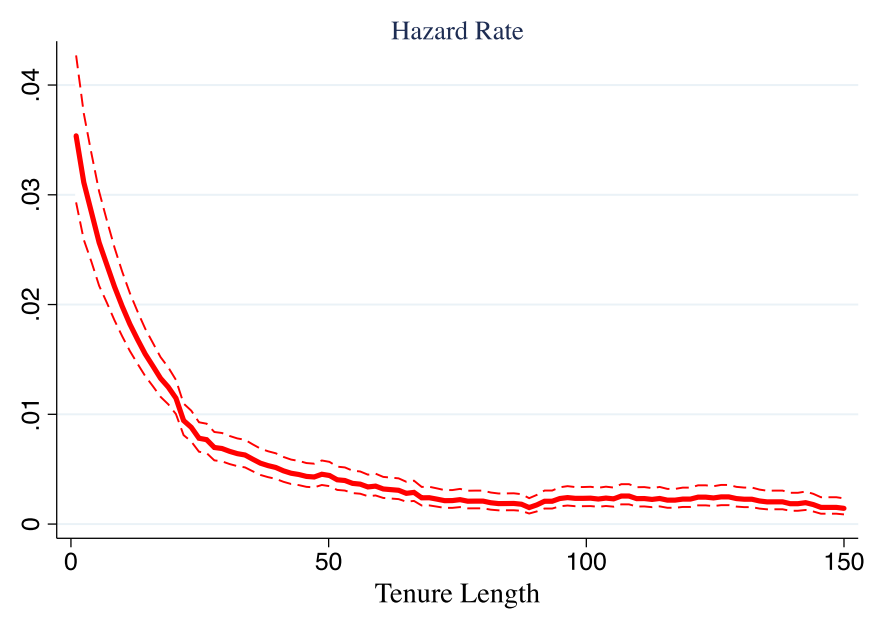

Fig. 3. Kaplan-Meier estimate of the hazard rate over tenure length with $95 \%$ confidence intervals. $^{34}$

negative shock. Therefore, older incumbents experience less frequent turnover. This prediction differs from that in the Ferejohn [37] model in which the replacement probability is constant and independent of tenure length. ${ }^{35}$

\subsection{Connection to empirical evidence}

While the focus of our paper is on our theoretical results, we next briefly discuss the extent to which the model is consistent with the empirical patterns on the relationship between political and economic cycles. The model suggests that policymakers are punished for negative economic shocks with shorter tenure and with lower rents. This pattern is consistent with the previous evidence which suggests that policymakers are kept or replaced in response to economic shocks (e.g., Fair [34], Lewis-Beck [44], Deaton and Miller [29], Achen and Bartels [4], and Wolfers [61]). As is the case in the model, it is often argued that these shocks are beyond the control of the policymaker, so that policymakers are effectively rewarded if they are lucky and punished if they are unlucky. In addition, Tella and Fisman [57] find that policymakers receive a pay increase whenever taxes decrease and whenever income increases. This is also consistent with the predictions of the model.

In related work not included here (see Ales et al. [8]), we supplement this previous work by considering the effect of commodity price shocks in developing countries. As has been well documented, commodity price shocks are an important source of business cycles in developing countries (e.g., Deaton [28]). In terms of our model, commodities are a funding source for many governments in developing countries, so that global shocks to commodity prices outside of policymakers' control can tighten or slacken the government budget constraint. Moreover, political turnover in these poorly institutionalized settings is not consistently determined by regularly held elections, but can often occur through coups, revolutions, or civil wars, and this is in line with the fact that turnover can occur in any period in our model. We find a number of empirical reg-

\footnotetext{
34 Smoothing performed using a rectangular smoothing kernel.

35 In addition to the results described here, we have also compared economies with different values of $\underline{V}$. We find that the lower is $\underline{V}$-and thus more slack the constraint on policymakers-the greater is the frequency of turnover.
} 
ularities which are consistent with the predictions of our model. Specifically, commodity price shocks which clearly affect income and investment also reduce the tenure of leaders and do so in a persistent fashion. Moreover, periods of turnover are associated with significantly depressed investment growth and tax revenue growth. Finally, the probability of turnover in the data is decreasing in the tenure length of the incumbent, as it is in the model.

Clearly, all of this empirical evidence on its own may have a number of explanations outside of the scope of the model. For example, in an environment in which both policymakers and citizens symmetrically learn about a policymaker's ability, one would find that an incumbent policymaker would be deemed incompetent and would lose office after a sequence of negative economic shocks. An additional prediction in such a framework would be that the probability of turnover declines with tenure length since an incumbent who has been in power longer is likely more competent, and this would be consistent with the evidence (see for example Jovanovic [40] and Garrett and Pavan [39]). Our model makes the same predictions regarding turnover, but it also additionally implies a greater risk of distortions-and thus, expropriation-following a sequence of negative economic shocks, and this prediction is much less straightforward to obtain in a symmetric learning model. In sum, while there may be other explanations for the various empirical regularities we have described, what our model shows is that all of these empirical patterns can be easily understood as the joint consequences of three political economy frictions.

\section{Conclusion}

In this paper, we have developed a framework where political and economic cycles are jointly determined by the interaction of three frictions: the non-benevolence of policymakers, limited commitment, and asymmetric information. In our analysis, we provide conditions under which long run distortions and long run turnover emerge. In addition, our model provides predictions regarding the dynamics of tenure, investment, and taxes which are qualitatively consistent with the empirical evidence on political and economic cycles.

Our model leaves several interesting avenues for future research. First, private government information in our setting is temporary since the shocks to the government budget are i.i.d. This assumption is not made for realism but for convenience since it maintains the common knowledge of preferences over continuation contracts and simplifies the recursive structure of the efficient sequential equilibria. Future work should consider the effect of relaxing this assumption. Second, we have assumed that all policymakers are identical, which implies that the only role for political replacement is that it incentivizes policymakers. In practice, replacement also functions as a means of selection. A natural extension of our framework would take into account both roles for replacement by allowing for multiple types of policymakers. Finally, because our economic environment is very stylized, we have not analyzed the quantitative implications of the model. Such an extension would incorporate additional layers of economic structure such as non-fully depreciating capital, sovereign debt, and an interaction between observable and unobservable economic shocks. This would allow us to quantitatively assess the amount of amplification and persistence which emerges from the addition of political economy frictions.

\section{Acknowledgments}

We would like to thank Alessandro Pavan and two anonymous referees, Marina Azzimonti, Sandeep Baliga, Chris Blattman, V.V. Chari, Gianluca Clementi, Gino Gancia, Mike Golosov, 
Brett House, Larry Jones, Thorsten Koeppl, Emi Nakamura, Torsten Persson, Benjamin Tengelsen, Aleh Tsyvinski and seminar participants at Stanford, the Nemmers Prize Conference on The Political Economy of Growth and Development, the Workshop on Macroeconomic Applications of Dynamic Games and Contracts, the 2013 SED meeting in Seoul and the 2013 Canadian Macroeconomics Study Group meeting in Toronto for comments. We would like to thank Sergei Kolbin for excellent research assistance. Maziero acknowledges support from the Cynthia and Bennett Golub Endowed Faculty Scholarship at Wharton.

\section{Appendix A. Supplementary material}

Supplementary material related to this article can be found online at http://dx.doi.org/10.1016/ j.jet.2014.07.004.

\section{References}

[1] D. Acemoglu, M. Golosov, A. Tsyvinski, Political economy of mechanisms, Econometrica 76 (3) (2008) 619-641.

[2] D. Acemoglu, M. Golosov, A. Tsyvinski, Dynamic Mirrlees taxation under political economy constraints, Rev. Econ. Stud. 77 (3) (2010) 841-881.

[3] D. Acemoglu, M. Golosov, A. Tsyvinski, Political economy of Ramsey taxation, J. Public Econ. (2010).

[4] C. Achen, L. Bartels, Blind retrospection: electoral responses to drought, flu, and shark attacks, Centro de Estudios Avanzados en Ciencias Sociales, working paper, 2004.

[5] M. Aguiar, M. Amador, Growth in the shadow of expropriation, Quart. J. Econ. 126 (2) (2011) 651-697.

[6] M. Aguiar, M. Amador, G. Gopinath, Investment cycles and sovereign debt overhang, Rev. Econ. Stud. 76 (1) (2009) $1-31$.

[7] R. Albuquerque, H. Hopenhayn, Optimal lending contracts and firm dynamics, Rev. Econ. Stud. 71 (2) (2004) 285-315.

[8] L. Ales, P. Maziero, P. Yared, A theory of political and economic cycles, NBER working paper (w18354), 2012.

[9] A. Alesina, Macroeconomics and politics, NBER Macroecon. Annu. (1988) 13-62.

[10] A. Alesina, R. Perotti, The political economy of budget deficits, National Bureau of Economic Research, Tech. rep, 1994.

[11] A. Alesina, N. Roubini, G. Cohen, Political Cycles and the Macroeconomy, MIT Press, 1997.

[12] A. Alesina, G. Tabellini, A positive theory of fiscal deficits and government debt, Rev. Econ. Stud. 57 (3) (1990) 403-414.

[13] S. Athey, K. Bagwell, Optimal collusion with private information, RAND J. Econ. (2001) 428-465.

[14] A. Atkeson, R. Lucas, On efficient distribution with private information, Rev. Econ. Stud. 59 (3) (1992) 427.

[15] M. Azzimonti, Barriers to investment in polarized societies, Amer. Econ. Rev. 101 (5) (2011) 2182-2204.

[16] J. Banks, R. Sundaram, Optimal retention in agency problems, J. Econ. Theory 82 (2) (1998) $293-323$.

[17] R.J. Barro, The control of policymakers: an economic model, Public Choice (1973) 19-42.

[18] R. Bates, When Things Fell Apart: State Failure in Late-Century Africa, Cambridge Univ. Pr., 2008.

[19] M. Battaglini, S. Coate, A dynamic theory of public spending, taxation, and debt, Amer. Econ. Rev. 98 (1) (2008) 201-236.

[20] C. Baylies, M. Szeftel, The fall and rise of multi-party politics in Zambia, Rev. African Polit. Economy 19 (54) (1992) 75-91.

[21] R. Bergoeing, P. Kehoe, T. Kehoe, R. Soto, A decade lost and found: Mexico and Chile in the 1980s, Rev. Econ. Dynam. 5 (1) (2002) 166-205.

[22] T. Besley, Principled Agents?: The Political Economy of Good Government, Oxford University Press, USA, 2006.

[23] B. Biais, T. Mariotti, J.-C. Rochet, S. Villeneuve, Large risks, limited liability, and dynamic moral hazard, Econometrica 78 (1) (2010) 73-118.

[24] R. Caballero, P. Yared, Future rent-seeking and current public savings, J. Int. Econ. 82 (2010) 1124-1136.

[25] V. Chari, P. Kehoe, Sustainable plans and debt, J. Econ. Theory 61 (2) (1993) 230-261.

[26] V. Chari, P. Kehoe, Sustainable plans and mutual default, Rev. Econ. Stud. 60 (1) (1993) 175.

[27] G. Clementi, H. Hopenhayn, A theory of financing constraints and firm dynamics, Q. J. Econ. 1 (1) (2006) $229-265$.

[28] A. Deaton, Commodity prices and growth in Africa, J. Econ. Perspect. 13 (3) (1999) 23-40. 
[29] A. Deaton, R. Miller, International commodity prices, macroeconomic performance, and politics in sub-Saharan Africa, in: Princeton Studies in International Economics, 1995.

[30] P.M. DeMarzo, M.J. Fishman, Agency and optimal investment dynamics, Rev. Finan. Stud. 20 (1) (2007) 151-188.

[31] P.M. DeMarzo, M.J. Fishman, Optimal long term financial contracting, Rev. Finan. Stud. 20 (6) (2007) 2079-2128.

[32] A. Drazen, The political business cycle after 25 years, NBER Macroecon. Annu. (2000) 75-117.

[33] G. Egorov, Political accountability under special interest politics, working paper, 2009.

[34] R. Fair, The effect of economic events on votes for president, Rev. Econ. Statist. 60 (2) (1978) 159-173.

[35] E. Farhi, C. Sleet, I. Werning, S. Yeltekin, Non-linear capital taxation without commitment, Rev. Econ. Stud. (2012), forthcoming.

[36] J. Fearon, Coordinating on democracy, Quart. J. Econ. (2010), forthcoming.

[37] J. Ferejohn, Incumbent performance and electoral control, Public Choice 50 (1) (1986) 5-25.

[38] Garrett, D., Pavan, A., Dynamic managerial compensation: on the optimality of seniority-based schemes. Center for Mathematical Studies in Economics and Management Science, Tech. rep., 2013.

[39] D.F. Garrett, A. Pavan, Managerial turnover in a changing world, J. Polit. Economy 120 (5) (2012) 879-925.

[40] B. Jovanovic, Job matching and the theory of turnover, J. Polit. Economy 87 (5) (1979) 972.

[41] N. Kovrijnykh, Debt contracts with partial commitment, Amer. Econ. Rev. 103 (7) (2013) 2848-2874.

[42] P. Krusell, J. Rios-Rull, On the size of us government: political economy in the neoclassical growth model, Amer. Econ. Rev. (1999) 1156-1181.

[43] J. Levin, Relational incentive contracts, Amer. Econ. Rev. 93 (3) (2003) 835-857.

[44] M. Lewis-Beck, Economics and Elections: The Major Western Democracies, University of Michigan Press, 1990.

[45] J. Li, N. Matouschek, Managing conflicts in relational contracts, Amer. Econ. Rev. 103 (6) (2013) 2328-2351.

[46] A. Pavan, I. Segal, J. Toikka, Dynamic mechanism design: a myersonian approach, Econometrica 86 (2) (2014) 601-653.

[47] T. Persson, L. Svensson, Why a stubborn conservative would run a deficit: policy with time-inconsistent preferences, Quart. J. Econ. 104 (2) (1989) 325-345.

[48] T. Persson, G. Tabellini, Political Economics, MIT Press, 2000.

[49] C. Phelan, On the long run implications of repeated moral hazard, J. Econ. Theory 79 (2) (1998) 174-191.

[50] V. Quadrini, Investment and liquidation in renegotiation-proof contracts with moral hazard, J. Monet. Econ. 51 (4) (2004) 713-751.

[51] D. Ray, The time structure of self-enforcing agreements, Econometrica 70 (2) (2002) 547-582.

[52] K. Rogoff, Equilibrium political budget cycles, Amer. Econ. Rev. (1990) 21-36.

[53] Y. Sannikov, A continuous-time version of the principal-agent problem, Rev. Econ. Stud. 75 (3) (2008) 957-984.

[54] N. Simutanyi, The politics of structural adjustment in Zambia, Third World Q. 17 (4) (1996) 825-839.

[55] Z. Song, K. Storesletten, F. Zilibotti, Rotten parents and disciplined children: a politico-economic theory of public expenditure and debt, Econometrica 80 (6) (2012) 2785-2803.

[56] S.E. Spear, C. Wang, When to fire a ceo: optimal termination in dynamic contracts, J. Econ. Theory 120 (2) (2005) 239-256.

[57] R. Tella, R. Fisman, Are politicians really paid like bureaucrats? J. Law Econ. 47 (2004).

[58] J. Thomas, T. Worrall, Income fluctuation and asymmetric information: an example of a repeated principal-agent problem, J. Econ. Theory 51 (2) (1990) 367-390.

[59] J. Thomas, T. Worrall, Foreign direct investment and the risk of expropriation, Rev. Econ. Stud. 61 (1) (1994) $81-108$.

[60] J. Thomas, T. Worrall, Dynamic relational contracts with credit constraints, working paper, 2010.

[61] J. Wolfers, Are voters rational? Evidence from gubernatorial elections, working paper, 2007. 